\title{
Grey Water Treatment For Smart Cities Using Iot
}

\author{
USHA.D, ANSLIN.J
}

\begin{abstract}
The paper proposes a grey water recycling system that will provide water to meet the needs of the house and irrigation purpose around the house. The water can be used for cleaning and flushing purposes. The grey water recycling system components were designed and they consist of piping system, diversion system, Filtration and storing system. The project includes collection tank, filtration tanks and storage tank. The filtering media used are Alum and Biosand.The filtered water is stored in storage tank and the overall process will be controlled by Arduino Mega, monitored by IoT Technology.
\end{abstract}

Keywords - filtration, activated charcoal, Solenoid valve, Grey Water, recycle.

\section{INTRODUCTION}

Water is one of our most precious resource and as much as wanted it to be, it is not an infinite resource. Water is all around the earth but only $2.5 \%$ of water is fresh water. A main problem that the world faces is to meet daily needs of water- 1 in 3 people around the world suffer as water isn't as accessible to them for their needs. People struggle to get water directly to communities far and near, and this problem gets worse due to climate change, deforestation, increased population and urbanization. As demand increases, keep digging deeper and deeper to find it.Groundwater supply has decreased up to 1 Meter and will continue to do so. Especially during summer, people are facing a major problem of groundwater depletion caused due to water pump out. Water scarcity is a serious threat to the environment. The water must be saved for our future generations. Saving water is not a big deal. Itcan be done in a simpler and effective ways. Thus an idea is being proposed on treatmentofgrey water and reuse it for our household uses.

\section{GREY WATER TREATMENT FOR SMART CITIES USING IOT}

The relatively waste water from baths, sinks, washing machines, and other kitchenappliances is called as Grey water.Our proposed paper mainly focuses on automating the filtration process of Grey water treatment and to reuse the treated waterfor cleaning and flushing purposes. Charcoal is used to remove contaminants and impurities. Charcoal carbon filters are most effective at removing chlorine, sediment, volatile organic compound from water. Level sensor is used in each tank for detection of level.The block diagram of the project is given below

Revised Manuscript Received on July 22, 2019.

USHA.D, Assistant Professor, Department of Electronics and Instrumentation Engineering, Jerusalem College of Engineering, Tamil Nadu, Chennai, India

ANSLIN.J, Assistant Professor, Department of Electronics and Instrumentation Engineering, Jerusalem College of Engineering, Tamil Nadu, Chennai, India

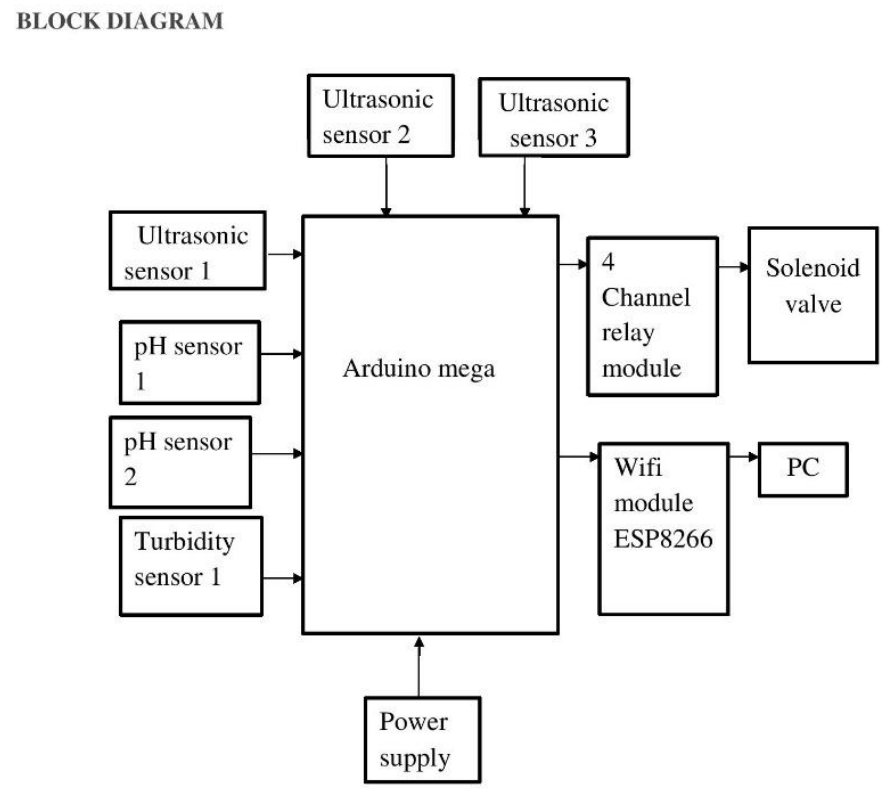

Fig 1: Block diagram of GWTSCI

To execute the unmanned Treatmentof the Grey water, first the waste water from the house is collected in tank 1 (Collection tank) and $\mathrm{pH}$ is measured using $\mathrm{pH}$ sensor.When water reaches certain level, the level sensor senses and opens the Solenoid valve to transfer the water to the next tank (Filtration tank), which contains alum solution. Grey water and Alum solution get mixed and reaches certain level. This level is sensed by level sensor and when it reaches the maximum level, solenoid valve gets open. The Alum treated grey water reaches tank 3(Filtration tank), which has tri-layer such as activated Charcoal, Sand and Pebbles. The level sensor performs the same process in tank 3 as tank 2.then the water reaches storage After the Grey water is treated, $\mathrm{pH}$ and Turbidity is measured to the treated water in the tank 4 (Storage tank ) and monitored using IoT.Thus the cleaning process is executed.

\section{HARDWARE IMPLEMENTATION}

\section{A.SENSOR SECTION}

\section{pH SENSOR}

pH Sensor is used for measurement of acidity and alkalinity, or the caustic and base present in a given solution. It is generally expressed with a numeric scale ranging from 0-14. The value 7 represents neutrality.Numbers on the scale increase with increasing alkalinity, while the numbers on the scale decrease with

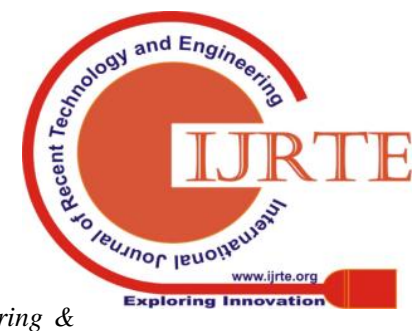

Blue Eyes Intelligence Engineering \& Sciences Publication 
increasing acidity. In the proposed project, $\mathrm{pH}$ sensor is used to measure the $\mathrm{pH}$ value of the Grey water before filtration in the Collection tank and also used to measure the $\mathrm{pH}$ of the treated water after Filtration in the Storage tank. $\mathrm{pH}$ of the treated water in the Storage tank is expected to be in the range of 7 approximately which means the neutral.

\section{TURBIDITY SENSOR}

Turbidity is the cloudiness or haziness of a fluid caused by large numbers of individual particles that are generally invisible to the naked eye, similar to smoke in air. The measurement of turbidity is a key test of water quality.Turbidity sensor measures the amount of light that is scattered by the suspended solids in water. As the amount of total suspended solids (TSS) in water increases, the water's turbidity level (and cloudiness or haziness) increases.In the Proposed project, the turbidity sensor directs a focused beam into the monitored water. The light beam reflects off particles in the water, and the resultant light intensity is measured by the turbidity sensor's photodetector positioned at 90 degrees to the light beam. The light intensity detected by the turbidity sensor is directly proportional to the turbidity of the water. Turbidity will be measured only after the Treatment of thegrey water in the Tank 4 (Storage tank).

\section{ULTRASONIC SENSOR}

Ultrasonic sensors emit short, high-frequency sound pulses at regular intervals. These propagate in the air at the velocity of sound. If they strike an object, then they are reflected back as echo signals to the sensor, which itself computes the distance to the target based on the time-span between emitting the signal and receiving the echo.In the Proposed Project, Each tank has separate Ultrasonic sensor for the level measurement except Tank 4 (Storage tank).Ultrasonic sensor emits high frequency sound waves towards the liquid in the tank. this high frequency waves gets reflect on hitting the surface of the liquid.The Reflected wave reaches the Receiver of the Ultrasonic sensor . Time taken by the wave to reach receiver after transmitted from the Transmitter of the same Ultrasonic Sensor is directly proportional to the distance between the Sensor and the liquid level.When the time taken is very low, level is detected and the Level sensor intimate the Solenoid valve to Open using Arduino Mega.thus, the level is detected in the Tank 1, Tank 2 and Tank 3.

\section{B.CONTROLLER SECTION}

In this system, the Arduino Mega 2560 microcontroller is used. It has 54 digital input and output pins , 16 analog inputs, 4 UARTs, a $16 \mathrm{MHz}$ crystal oscillator, a USB connection, a power jack, an ICSP header, and a reset button. It contains everything needed to support the microcontroller; simply it is connected to a computer with a USB cable or powers it with a AC-to-DC adapter or battery to get started. It can be programmed with the Arduino software. The Atmega2560 on the Arduino Mega comes pre-burned with a boot loader that allows you to upload new code to it without the use of an external hardware programmer. It communicates using the original STK500 protocol.

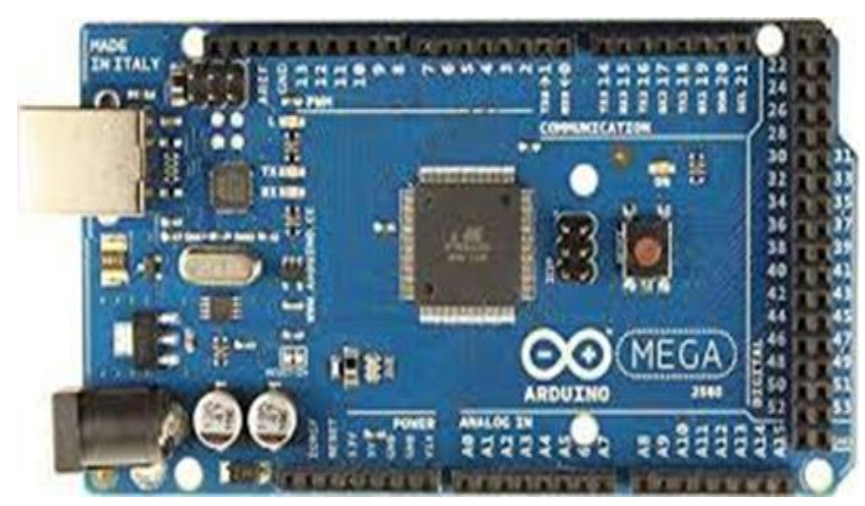

\section{C.WIFI MODULE SECTION}

\section{ESP8266}

To provide microcontroller access to the WiFi network ESP8266 WiFi Module can be used . In the Proposed Project, ESP8266 wifi module is used to Transmit the measured values of $\mathrm{pH}$ and Turbidity to Monitoring System using Internet of Things. ESP8266 is a $3 \mathrm{~V} \mathrm{WiFi} \mathrm{module} \mathrm{very}$ popular for its Internet of Things applications. ESP 8266 maximum working Voltage is $3.6 \mathrm{~V}$.

\section{D.OUTPUT SECTION}

\section{4-CHANNEL RELAY}

A relay is an electrically operated switch. To operate a switch relays use an electromagnet, but other operating principles such as solid-state relays were also applied. Relays are used to control a circuit by a separate low-power signal, or where several circuits must be controlled by one signal. In the Proposed Project, After the detection of maximum level of water in the tanks, the Solenoid valves are need to be open. Since Arduino provides only 5V to Solenoid valve while, it needs $12 \mathrm{~V}$ to Open.To get the Required voltage of $12 \mathrm{~V}$, 4-Channel Relay Module was integrated with Solenoid valve. 4-Channel Relay Module draws 5V from Arduino Mega and boosted to $12 \mathrm{~V}$.This Boosted voltage of $12 \mathrm{~V}$ will be provided to SoleniodValve.Thus, the Solenoid valve open

\section{IV.SCHEMATIC DIAGRAM}

Schematic diagram of the Automated Grey water treatment is given below

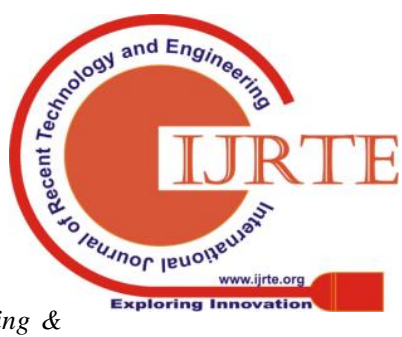




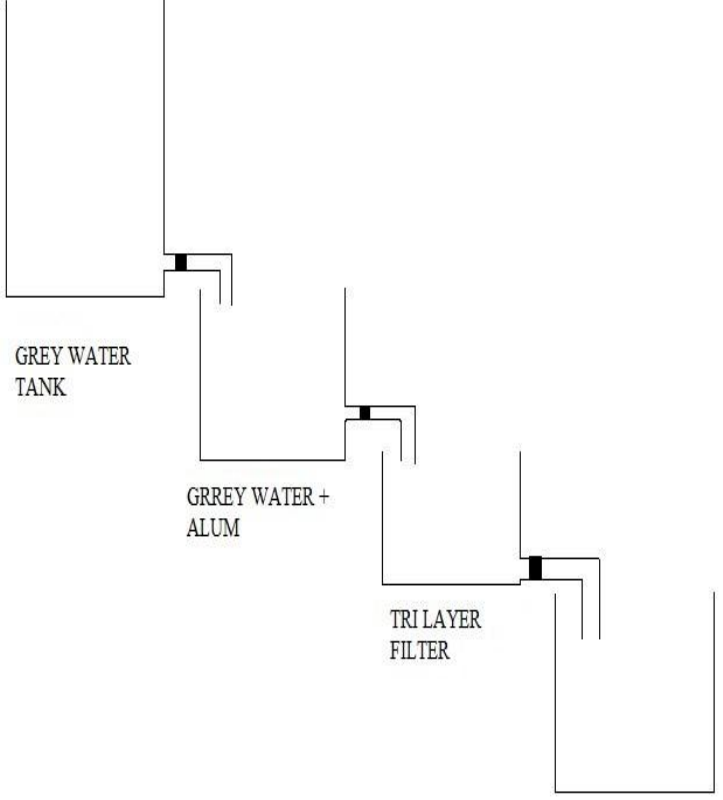

FILTERED WATER

\begin{tabular}{|l|l|}
\hline CONTENTS & $\mathrm{pH}$ VALUE \\
\hline DISTILLED WATER & 7.01 \\
\hline SOAPY WATER & 9.71 \\
\hline $\begin{array}{l}\text { SOAPY WATER } \\
\text { WITH ALUM }\end{array}$ & 3.2 \\
\hline TREATED WATER & 7.62 \\
\hline
\end{tabular}

\section{CONCLUSION}

The Automated Grey water treatment System proposed can greatly eliminate the scope of manual labour, While cities moving towards solutions which can diminish the existing problems in water treatment systems. It can be installed for cleaning toilets, Gardening, Vessel washing and Furthermore, it can be used for Floor washing in home. The growing emphasis on smart cities and environment friendly alternatives necessitate a technologically competent means of combating the problem of water demand .This Automated Grey water treamentSystem seeks to achieve exactly the same. The system is more eco-friendly as well as having fully automatic operation. The installation cost and time required for installing this system are very less.

\section{REFERENCES}

1. Niel Andre Cloete, Reza Malekian And Lakshmi Nair"Design of Smart Sensors for Real-Time Water Quality Monitoring ,'IEEE Access, volume 4,August 2016.

2. AlifSyarafi Mohamad Nor, Mahdi Faramarzi, MohdAmri Md Yunus, and SallehuddinIbrahim"Nitrate and Sulfate Estimations in Water Sources Using a Planar Electromagnetic Sensor Array and Artificial Neural Network Method," IEEE SENSORS JOURNAL, VOL. 15, NO. 1, JANUARY 2015.

3. Theofanis P. Lambrou,Christos C. Anastasiou, Christos G. Panayiotou, andMarios M. Polycarpou“A Low-Cost Sensor Network for Real-Time Monitoring and Contamination Detection in Drinking Water Distribution Systems , "IEEE SENSORS JOURNAL, VOL. 14, NO. 8, AUGUST 2014

4. T. P. Lambrou, C. G. Panayiotou, and C. C.Anastasiou, "A low-cost system for real time monitoring and assessment of potable water quality at consumer sites," in Proc. IEEE Sensors, Oct. 2012, pp1-4.

5. Pedro M. Ramos, J. M. Dias Pereira, Helena M. Geirinhas Ramos and A. Lopes Ribeiro"A Four-Terminal Water-Quality-Monitoring Conductivity Sensor",IEEE TRANSACTION SON INSTRUMENTATION AND MEASUREMENT, VOL. 57, NO. 3, MARCH 2008.

6. Louis COETZEE, Johan EKSTEEN, "The Internet of Things - Promise for the Future? An Introduction," ISTAfrica2011 Conference Proceedings, Paul Cunninghamand Miriam Cunningham (Eds), IIMC International Information Management Corporation, 2011, pp. 1-9.

7. E. Fleisch, What is the Internet of Things: An Economics Perspective, Auto ID Labs White Paper,WP-BIZAPP-053, Jan. 2010.

8. Zaigham Mahmood, "Cloud Computing: Characteristics and Deployment Approaches," 11th IEEE International Conference on Computer and Information Technology, UK, 2011, pp. 121-126. 